\title{
Energy-Based Devices for Functional Vaginal Problems: Issues and Answers
}

\author{
Alyssa Bujnak $^{1}$ (D) C Carly A. Crowder ${ }^{1} \cdot$ Michael L. Krychman ${ }^{1}$
}

Accepted: 26 January 2021 / Published online: 26 February 2021

(C) The Author(s) 2021

\begin{abstract}
Vaginal rejuvenation is a marketing term that encompasses surgical and medical treatments for functional vaginal/vulvar problems including but not limited to genitourinary syndrome of menopause (GSM), sexual dysfunction, vaginal laxity, and stress urinary incontinence (SUI) and for esthetic concerns including dissatisfaction with vulvovaginal appearance. Multiple treatment options have become available for indications of functional vaginal problems. Noninvasive management options including the use of more novel treatments such as energy-based devices have gained interest. Previously, studies regarding the efficacy and safety of the energy-based devices for functional vaginal problems were mostly limited to cohort studies without sham treatment, control groups, randomization, or double blinding. As a result of this insufficient data in 2018, the FDA released a statement of warning against the use of energy-based devices in the treatment of functional vaginal problems or vaginal cosmetic procedures (Https://Www.Fda.Gov/Medical-Devices/Safety-Communications/Fda-Warns-Against-Use-Energy-Based-Devices-PerformVaginal-Rejuvenation-or-Vaginal-Cosmetic. 1-4, 2018).

Purpose of Review This article reviews the most current treatment modalities in the realm of vaginal rejuvenation therapy with an emphasis on the efficacy and safety of the energy-based devices.

Recent Findings In the most recent literature, there have been studies with improvements in study design that support the efficacy and the short-term safety of the energy-based devices.

Summary More recent studies with improved study design evidence that the use of energy-based devices results in improvements in functional vaginal problems and that serious adverse events appear to be rare. The availability of these devices as treatment options for functional vaginal problems has the potential to impact patient by improving their symptoms and quality of life. Caution still remains however regarding their safety following a longer period of time after their use.
\end{abstract}

Keywords Vaginal rejuvenation · Laser · Radiofrequency · Genitourinary syndrome of menopause · Vaginal laxity $\cdot$ Sexual dysfunction

\section{Introduction}

Vaginal rejuvenation is a nonmedical term that describes procedures that alter the cosmetic appearance of vulvovaginal tissue and may treat functional vaginal problems including vaginal laxity (VL), sexual dysfunction, genitourinary syndrome of menopause (GSM), and stress urinary incontinence

Alyssa Bujnak

abujnak@hs.uci.edu

1 Department of Obstetrics and Gynecology, UC Irvine Medical Center, 333 City Blvd. West \#1400, Orange, CA 92868, USA
(SUI). As so-called vaginal rejuvenation procedures can alter the cosmesis of the vulvovaginal tissues, these treatments may also be aimed at improving dissatisfaction with vulvovaginal anatomy [1-3]. All of these symptoms and syndromes are prevalent and have been noted to affect women's quality of life (QOL).

Women's interest in cosmetic genital procedures related to dissatisfaction with their vulvovaginal appearance has increased over recent years. This perception of inferior appearance is potentially a result of inaccurate information about normal variations in genital anatomy and depictions in the media [4]. Genitourinary syndrome of menopause includes signs of vulvovaginal atrophy (VVA), which describes the appearance of the vulva and the vagina secondary to post- 
menopausal effects of estrogen deficiency. GSM also includes the range of symptoms associated with the physical changes of the vulva and the vagina that include genital (irritation, dryness, burning), sexual (dyspareunia, discomfort), and urinary (recurrent urinary tract infections, urgency) [5]. GSM affects approximately $50 \%$ of women and has been shown to impact sex, relationships, and quality of life [6, 7]. Vaginal laxity (VL) is also a concern for many women. Vaginal laxity is a complex, multifactorial condition that is inadequately defined and not universally accepted. Despite the aforementioned complexity, VL has been studied and categorized by vulvovaginal anatomic location and symptomatology including functional or esthetic [8]. A relevant study showed that $50 \%$ of parous women were concerned about vaginal laxity, and $80 \%$ of these women did not discuss this concern with their obstetrician/gynecologist [9]. Vaginal laxity has been associated with patient reported sexual dysfunction, urinary incontinence, and decreased quality of life [10]. Sexual dysfunction has been shown to cause psychological distress in $43 \%$ of women during their lifetime [11]. The prevalence of urinary incontinence (UI) in women between the ages of 30-90 years old has been found to be $45 \%$, with most of these women reporting SUI as the main component; UI has also been noted to impair women's quality of life [12].

Treatments under the umbrella term "vaginal rejuvenation" aim to correct and restore the vulvovaginal tissues to in turn alleviate the above signs and symptoms that women commonly experience [2]. The physiology of menopause, along with vaginal trauma from parturition, is one of the inciting factors that lead to GSM, VL, sexual dysfunction, SUI, and dissatisfaction with vulvovaginal appearance. Menopause results in estrogen deficiency which leads to diminished production of elastin and collagen in the vulvovaginal tissues, causing a decrease in vaginal elasticity and subsequent thinning of the vaginal epithelial lining $[7,13,14]$. Concentration of glycogen in the vaginal epithelium also declines as a result of hypoestrogenic status, which promotes changes in the normal vaginal flora and $\mathrm{pH}[14 \bullet]$. Blood flow and secretions in the vagina also decrease as a result of lower estrogen levels [15].

Both surgical procedures and noninvasive therapies are included in treatment options for both functional vaginal problems and dissatisfaction with vulvovaginal appearance. Surgical and invasive options include labiaplasty, perineoplasty, vaginoplasty, and G-spot amplification, platelet-rich plasma (PRP), and lipofilling [16]. Noninvasive options include first-line treatments such as vaginal lubricants, moisturizers, and topical estrogen, while newer treatments include energy-based devices $[2,17]$. This article reviews the most common treatments available under the array of "vaginal rejuvenation" with focus on the efficacy, safety, and current perspectives of the use of energy-based devices for functional vaginal problems. Surgical procedures and other invasive therapies will not be further discussed as they are beyond the scope of this review; however, Wilkie et al. [18] provide a thorough review of the literature.

\section{Methods}

We conducted a retrospective review of research related to the term vaginal rejuvenation, focusing on publications within the last 5 years, from 2016 to 2020 . We aimed to describe this term based on the current evidence in the literature and discuss common and trending therapies under the umbrella of vaginal rejuvenation. Studies were identified by systematic search of PubMed, Google Scholar, and Cochrane Library. A combination of the following search terms were used: "vaginal rejuvenation," "vaginal tightening," "energy-based devices," "laserbased devices," " $\mathrm{CO}_{2}$ laser," "radiofrequency," "vaginal laxity," "genitourinary syndrome of menopause," "vaginal cosmetic procedure," "safety," "FDA," "female genital cosmetic surgery," "vaginal treatment," "PRP," "platelet-rich plasma," "labiaplasty," "vaginoplasty." Articles were excluded if they were not in English or if they were out of the publication date range. A total of 66 articles retrieved through the database search and 10 additional articles ( [19-28]) identified through citations within these sources were reviewed in detail by the authors.

\section{Surgical Therapy}

The term "vaginal rejuvenation" also encompasses genital procedures aimed to reduce vaginal laxity and enhance sexual function. Genital procedures include, but are not limited to, labiaplasty, perineoplasty, and vaginoplasty [29]. Additional surgical therapies include g-spot amplification (via injections of hyaluronic acid or autologous fat transfer) and vaginal rugation restoration. Newer procedure such as platelet-rich plasma (PRP) and lipofilling can also be considered in this category. Current research on these techniques is mostly expert opinion, case series, and case reports as they are newer techniques; thus, safety and efficacy profiles are very limited $[16,29]$. Surgical interventions may alter the cosmesis of the genital tissue and/or act to eliminate some functional complaints. For example, women with elongated and asymmetrical labia may complain of poor cosmetic appearance (esthetic complaint); additionally, they may have functional complaints such as chaffing and or the labia dragged into the vagina during intercourse resulting in painful intercourse.

Other nonhormonal treatment options include PRP and lipofilling or fillers.

The use of lipofilling and PRP for functional vaginal problems has been described in case reports, but has not been widely studied. Lipofilling involves depositing autologous fat in the vulvovaginal tissues to restore the soft tissues; there is the potential for the fatty tissue to contain stem cells which 
may aid in tissue regeneration at the implantation sites. The process of PRP involves the injection of autologous plasma with high platelet fraction into the vulvovaginal tissues. The PRP which is rich in growth factors may promote tissue repair, angiogenesis, and inflammation [30].

\section{Noninvasive Therapy}

Noninvasive strategies for functional vaginal problems have the benefit of avoiding the potential morbidity of surgery. Current noninvasive standard of care treatment for GSM includes vaginal topical estrogen, moisturizers, and lubricants. Vaginal moisturizers are typically water-based products that are applied to the vaginal tissues regularly to treat vaginal dryness symptoms. Lubricants are applied to the genital tissue as needed to reduce symptoms of dyspareunia and decrease coital pain. Both moisturizers and lubricants are aimed at alleviation of symptoms of GSM as compared to vaginal estrogen which has the ability to revitalize the underlying vaginal tissues [6]. While topical estrogens are effective in some patients, there are groups of patients with contraindications to hormonal therapy and patients in which self-application of topical therapies is not feasible. Specifically, the use of topical estrogen is controversial in women with a history of breast cancer, estrogen sensitive tumors, including some gynecologic cancers, and thromboembolism due to the fact that these conditions are potentially responsive to serum estrogen levels [14•]. At this point, studies cannot conclude with certainty that topical estrogen does not increase serum estrogen level to a clinically significant degree of provocation in these diseases [31]. Most studies suggest that topical estrogen can be considered for patients with a history of breast cancer and some gynecologic cancers with shared decision-making when GMS is refractory to other treatment lines and without certain high risk features; however, it is stressed that there is insufficient high-quality evidence regarding the risks [31, 32]. Patients with breast cancer often have severe GSM as a result of hypoestrogenism following treatment with chemotherapy, GnRH agonists, or anti-estrogen therapy [33]. Alternative noninvasive methods that are nonhormonal may be the only option for some of the aforementioned patients with significant GSM and inability or reluctance to use topical estrogen.

\section{Energy-Based Interventions}

Energy-based devices apply the energy of radiofrequency (RF) or a laser to the vulvovaginal tissue to induce remodeling and revitalization of tissues [19॰]. There are two types of lasers commonly used to treat vulvovaginal tissue, carbon dioxide $\left(\mathrm{CO}_{2}\right)$ and erbium:yttrium-aluminum-garnet (Er:YAG). All of the aforementioned devices have been used in dermatologic practice in rejuvenation of the face and neck with evidence for efficacy and safety [2]. Numerous studies have shown that the energy-based devices show promising efficacy in the treatment of GSM, vaginal laxity, sexual dysfunction, potentially SUI, and improvements in QOL; however, previously, very few of these studies reduced bias in the form of randomization, control groups, blinding, and sham treatments.

In addition to their promising efficacy, the energy-based devices have been shown to be cost-effective, and do not require sedation or downtime for patients. Wallace et al. [34] conducted a retrospective review study in 2020 comparing the cost-effectiveness of vaginal estrogen, ospemifene, and vaginal $\mathrm{CO}_{2}$ laser therapy. All treatments were found to be costeffective; however, they found vaginal $\mathrm{CO}_{2}$ laser therapy to be the most cost-effective when assuming the following based on published data in their review of the research: typical adherence rates of the three treatment options, efficacy of the treatments, and patient costs for each treatment. While the findings are promising for the energy-based devices, it must be mentioned that the typical adherence rate for vaginal $\mathrm{CO}_{2}$ laser therapy was assumed based on adherence rates to other inoffice procedures such as percutaneous tibial nerve stimulation and on data from RCTs which is significant given the fact that the researchers found that the variable that most influenced the cost-effectiveness results was adherence to the treatment regimen. Additionally, the cost of each treatment was estimated based only on patient cost and did not evaluate physician office and hospital costs [34].

Another attraction to these devices is safety. Current data reports the energy-based devices to be well tolerated and result in limited and infrequent complications [35]. There remains limited data on long-term safety and currently there is unawareness of the optimal treatment duration and when to offer patients a repeat procedure. With the above benefits considered, the use of energy-based devices for the treatment of GSM, VL, sexual dysfunction, and urinary incontinence has become widespread. In a recent global survey conducted by Gambacciani et al. [36] among practitioners using the vaginal erbium laser, it was reported that among only 535 responding practitioners, a total of 113,174 patients spanning six continents were treated from 2012 to 2019.

\section{Lasers}

\section{$\mathrm{CO}_{2}$ Laser}

The $\mathrm{CO}_{2}$ laser produces heat which causes certain proteins to denature and trigger the expression of growth factors including TGF-beta, which is responsible for activation of the fibrogenic process. The efficacy of the $\mathrm{CO}_{2}$ laser treatment in revitalizing the vulvovaginal tissues has been demonstrated in multiple histological studies. Gaspar et al. [20•] conducted a randomized control trial (RCT) in 2011 in women with GSM. The control group underwent treatment with platelet-rich plasma (PRP) and pelvic exercises, while the study group 
underwent treatment $\mathrm{CO}_{2}$ laser therapy, $\mathrm{PRP}$, and pelvic exercises. In the study group, histologic specimens showed an increase in fibroblast activity, fibrillar components, and neogenesis in the extracellular matrix, as well as improved thickness of the vaginal epithelium and the concentration of glycogen within the epithelium [20•]. In 2015, Zerbinati et al. [21] performed biopsies of vaginal mucosa on 50 postmenopausal women with GSM before and after treatment with $\mathrm{CO}_{2}$ laser therapy. Following the treatment, they observed increased thickness of the vaginal epithelium with increased storage of glycogen within epithelial cells as well as activation of fibroblast synthesis of collagen in the lamina propria [21]. In comparison, topical estrogen therapy has predominantly shown only increased epithelial layers [22].

As previously mentioned, numerous studies have noted significant improvement in GSM, VL, sexual function, and QOL following treatment with vaginal $\mathrm{CO}_{2}$ laser therapy (Table 1) [20, 22, 23, 38, 39, 42]. Improvement in urinary incontinence has not been reported with $\mathrm{CO}_{2}$ laser therapy. Despite the large number of studies showing efficacy for GSM, VL, sexual function, and QOL, the majority of the studies previously performed were prospective cohort studies with limitations based on study design. These studies can be reviewed in Table 1. Here, studies that are more contemporary and have fewer limitations or new populations of patients not previously studied will be discussed.

Cruz et al. [14-] performed one of the first studies of vaginal $\mathrm{CO}_{2}$ therapy for GSM treatment with a design that was randomized, controlled, and double-blinded with a sham treatment. Post-menopausal women $(N=45)$ with GSM were randomly assigned for treatment groups including (laser + sham + vaginal estrogen), (laser + vaginal estrogen), or (vaginal estrogen + sham laser). A greater degree of GSM symptoms improved in the groups that received $\mathrm{CO}_{2}$ laser therapy compared to the group that received only vaginal estrogen. Sexual function only improved in the group that received laser and vaginal estrogen therapy [14•]. In a recent study, Ruanphoo et al. [43 $]$ performed a randomized control trial that was double-blinded and sham-controlled $(N=88)$ with postmenopausal women experiencing GSM. The study group received laser treatment and the control group received a sham treatment. There were significant improvements in the Vaginal Health Index (VHI), which clinically evaluates vulvovaginal atrophy, and the Visual Analog Scale (VAS), which evaluates symptoms of GSM, compared to the control group, but there was no difference in urinary incontinence symptoms [43•]. In 2019, Paraiso et al. [37•] studied the effects of laser therapy versus vaginal estrogen in postmenopausal women with GSM in a randomized control trial that was single-blinded ( $N=62$ ). Results showed improvement in GSM and sexual function in both groups, but did not find a significant difference between the two groups [37•]. Eftekhar et al. [41•] recently completed a randomized control trial
$(N=50)$ in which post-menopausal women with GSM received laser treatment or vaginal estrogen. This study found no significant improvement in VHI between the groups, but did find that there was greater improvement in sexual function in the laser group [41•].

Perrone et al. [40] conducted a prospective cohort study in which $(N=43)$ patients suffering from vaginal shorting, atrophy, and stenosis following radiation therapy for gynecologic cancers received treatment with $\mathrm{CO}_{2}$ laser therapy which showed improvement in vaginal length and VHI [40]. Moreover, Pieralli et al. [7] reported in a prospective cohort study improvement in VHI and VAS in patients $(N=50)$ with a history of breast cancer and with resultant oncologic menopause following treatment with vaginal $\mathrm{CO}_{2}$ laser therapy [7].

\section{Erbium:Yttrium-Aluminum-Garnet}

The Er:YAG laser has been used similarly for the indications of VL, and GSM; it has also been used more commonly than $\mathrm{CO}_{2}$ laser for the indication of SUI and has recently been shown to improve QOL. This laser has a wavelength of $2940 \mathrm{~nm}$ that emits energy in the mid-infrared light spectrum [2]. The laser exposes the collagen tissue to heat which results in contraction of the collagen inducing the wound healing cascade which stimulates fibroblasts to synthesize collagen $[19,25,44]$. The efficacy of the Er:YAG laser on revitalizing the vulvovaginal tissue has been shown in histologic studies. Lapii et al. [44] conducted a study in which vaginal biopsies were obtained $(N=18)$ from patients with SUI before exposure to Er:YAG laser and 1-2 months post-treatment with Er:YAG laser. Morphometric results showed increased epithelial glycogen content and epithelial layer thickness by $64.5 \%$, increase in active fibroblasts and neocollagenogenesis, and increased density of capillaries [44].

Clinical studies of efficacy of Er:YAG for functional vaginal problems have primarily been limited to prospective cohort studies thus far. Multiple prospective cohort studies have reported effectiveness of the Er:YAG laser in management of vaginal laxity, GSM, sexual dysfunction, and SUI (Table 2) $[19,20,25,26,48,49]$. One study performed by Gambacciani et al. [19•] compared Er:YAG laser to vaginal estrogen therapy for treatment of GSM $(N=70)$. The study group received one treatment with the Er:YAG laser monthly for 3 months, while the control group received standard treatment with vaginal estrogen twice weekly for the 3-month period. On evaluation at 3 and 6 months post-treatment, VAS and VHI improved in both groups but significantly more improved in the group treated with laser [19॰]. A more recent prospective cohort study by Reisenauer et al. [49] reported that among patients $(N=30)$ receiving two treatments with Er: YAG laser therapy, patients reported a significant improvement in QOL, which had previously not been reported. 


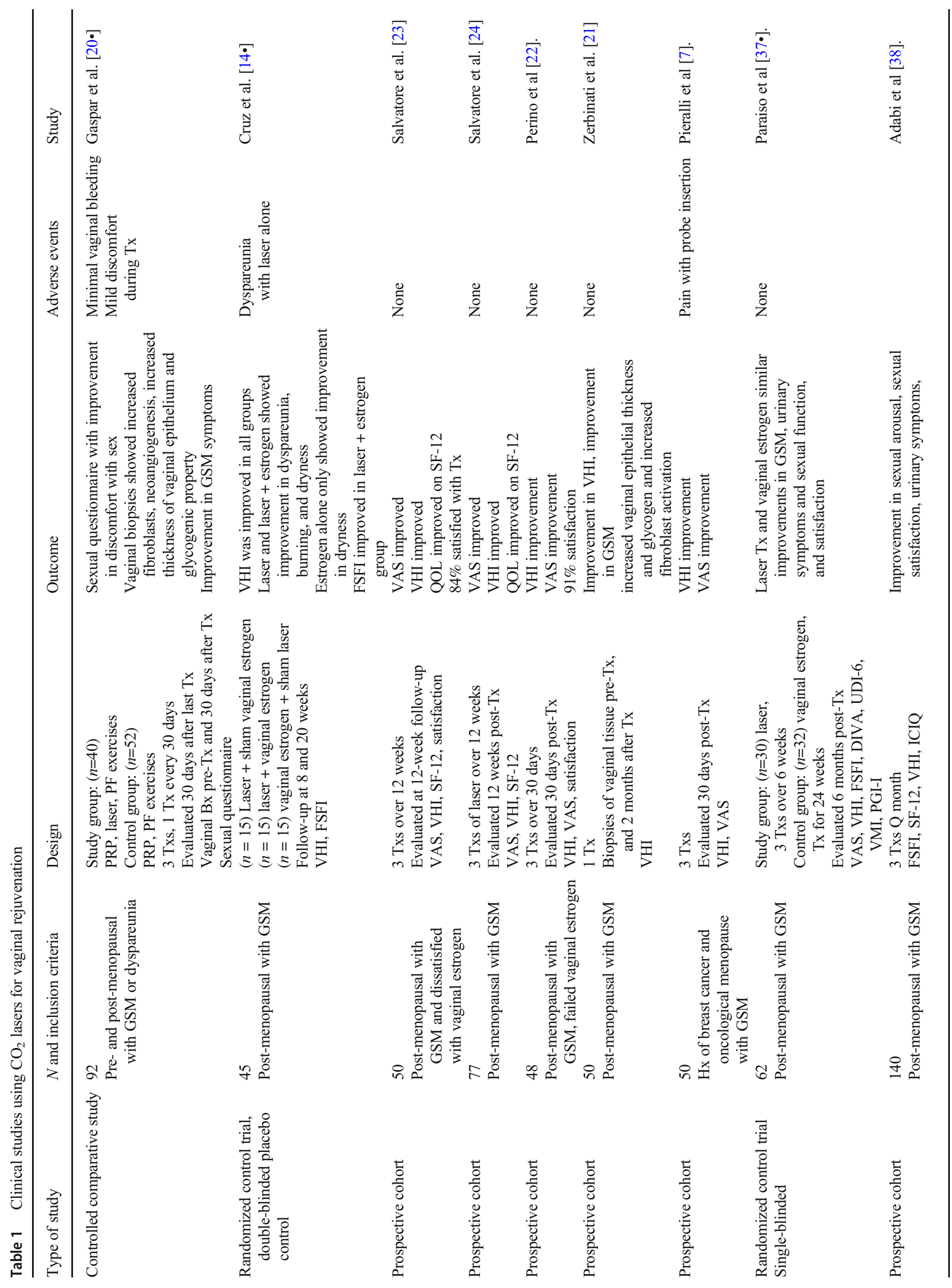




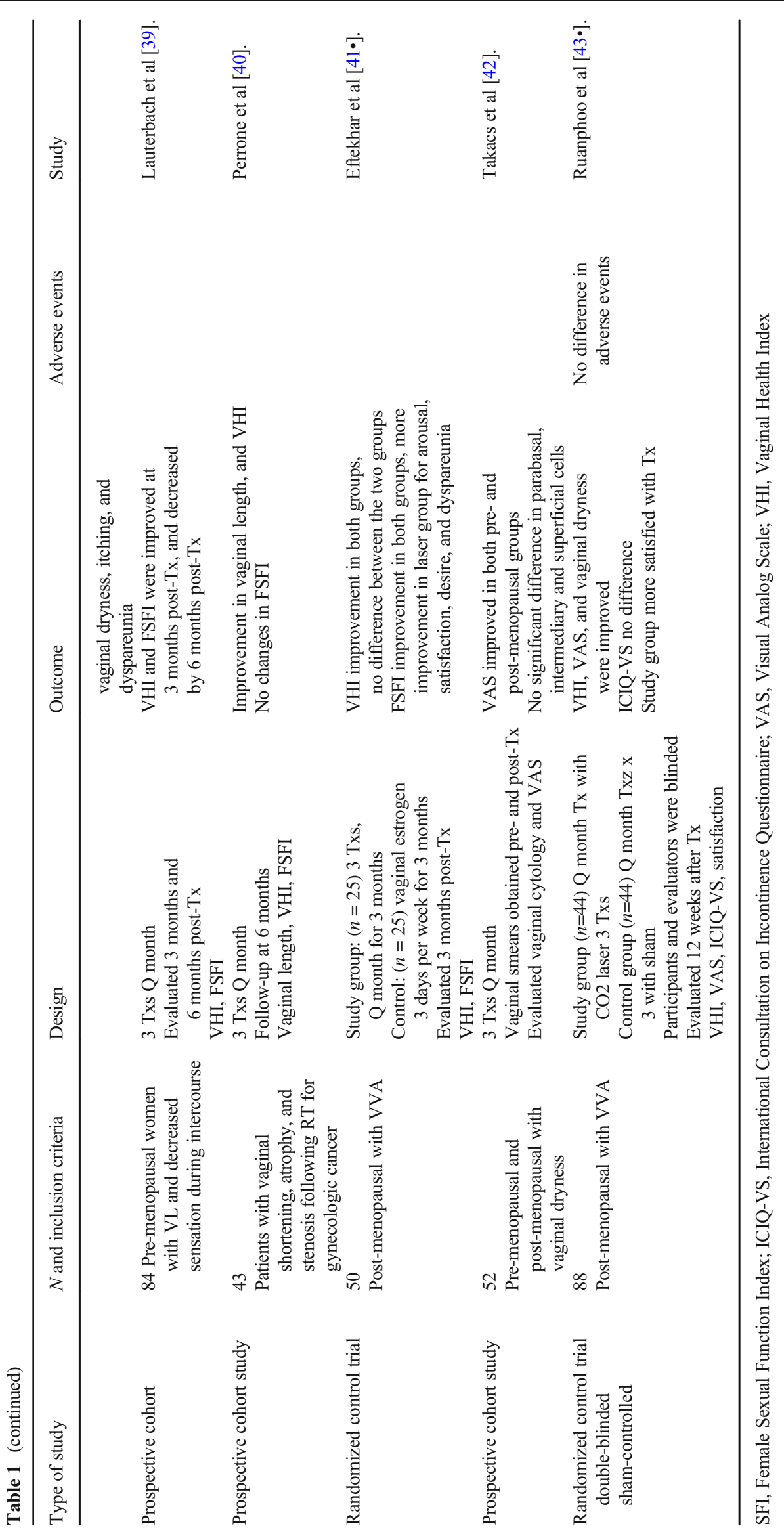




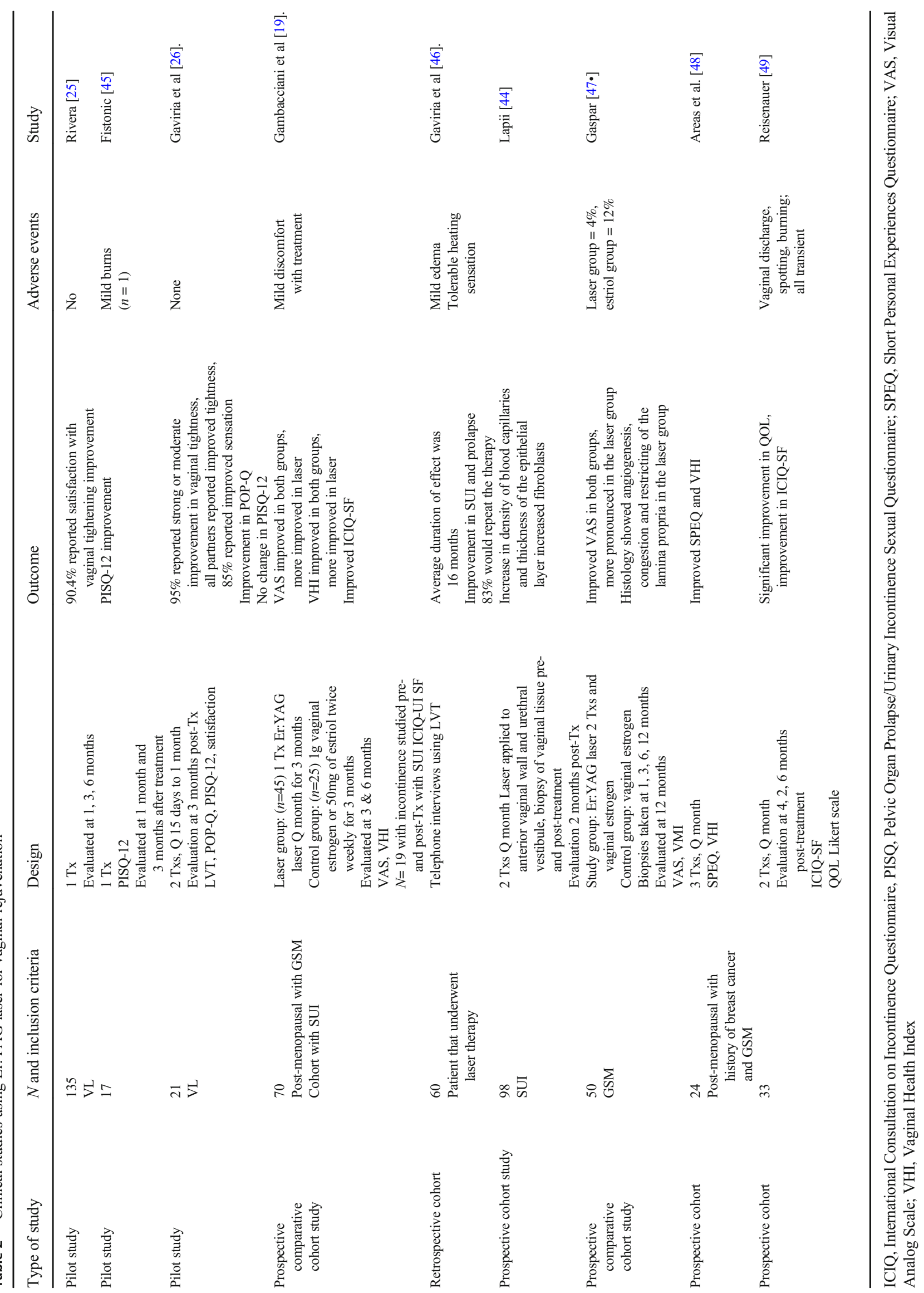




\section{Radiofrequency Therapy}

In treatments of the vulvogaginal tissue with radiofrequency (RF) therapy, a device emits focused electromagnetic waves to generate heat that is applied to tissue. Heating of the tissue's collagen fibers leads to folding of its triple helix structure which causes the fibers to become thicker and shorter. Furthermore, this process causes a mild inflammatory response which activates fibroblasts for collagen and elastin synthesis $[2,50,51]$. The efficacy of this process has been shown histologically. Kent et al. conducted a study to evaluate histologic evidence of the efficacy of RF treatment on vulvovaginal tissue using an animal model of multiparous swine. The swine were administered RF treatment once per week for 3 weeks; biopsies were collected at baseline and at week four. The histology showed an increased density of elastin and collagen fibers after treatment with RF. A histologic study on post-menopausal women $(N=20)$ by Leibaschoff et al. [52•] found that following three treatments with RF in the study group versus a sham treatment in the control group, biopsies of the study group showed increased concentration of collagen.

Regarding clinical studies, numerous prospective cohort studies have shown that RF is potentially effective as therapy for vaginal laxity, GSM, sexual dysfunction, improvement in QOL, and, notably, SUI $[27,28,45,51,53-56]$. In the past few years, there have been reports of efficacy for RF in treatment of functional vaginal problems as well as improvements in QOL in randomized control trials as well $[52,57,58]$ (Table 3). Leibaschoff et al. [52•] performed a doubleblinded randomized control trial in 2016 in which $(N=20)$ post-menopausal women with SUI and vaginal laxity were randomized into either the study group which was administered 3 treatments with RF therapy, or randomized into the control group which was given 3 treatments with a sham device; a double-blinded method was used. Results showed improvement in SUI including $70 \%$ with negative post-treatment cough stress test, and improvement in VHI and VAS [52•]. In 2017, Krychman et al. [57 $]$ performed a randomized placebo sham-controlled and blinded study in which pre-menopausal women $(N=174)$ with VL were randomized to a study group which received 1 treatment with $\mathrm{RF}$, and a control group which received 1 treatment with a sham device. At a 6month evaluation, there was significant improvement in vaginal laxity and sexual function in the group treated with RF [57•]. Most recently, in 2020, Allan et al. [58•] completed a randomized control study in which $(N=35)$ women with SUI were randomized to receive either one or two treatments with RF. When evaluated at 12 months post-treatment, both groups had improvements in SUI and QOL [58•].

Another interesting study regarding RF conducted by Sarmento et al. [59] in 2020 is a prospective cohort study in which post-menopausal women with GSM underwent 3 treatments with RF. At timepoints throughout the treatment course, vaginal smears were obtained and assessed. Compared to baseline, there was a significant increase in the concentration of lactobacillus species, a decrease in the vaginal $\mathrm{pH}$, increased amount of parabasal cells and superficial epithelial cells, and improvement in VHI score and GSM [59].

\section{Safety of Energy-Based Devices}

Multiple prospective studies that were reviewed in which the energy-based devices were used for vulvovaginal treatments reported minimal or no adverse events, and none of the studies reported severe adverse events. The mild adverse events in the studies reviewed were dysuria, discomfort during treatment, urinary tract infection, vaginal discharge, edema, vaginal bleeding, vaginitis, and mild vaginal burn. Other sources report side effects may include itching, burning, or swelling that occurs immediately after the procedure and acutely resolves, bacterial vaginosis, UTI, and rarely the development of scarring $[60,61]$. In a recent editorial, Delancey [62] voiced concern that while the tissue initially appears re-vascularized following laser or RF treatments over time the tissue would become avascular and form scar tissue similar to other wound healing processes.

The study by Wallace et al. [34] previously discussed found that there was less probability of side effects or complications when using $\mathrm{CO}_{2}$ vaginal laser therapy compared to vaginal estrogen. Additionally, in a prospective cohort study conducted by Donato et al. [35] ( $N=53)$ to evaluate satisfaction and safety of treatment of GSM with $\mathrm{CO}_{2}$ vaginal laser therapy, only acute and minor complications were reported including minor bleeding with insertion of the treatment probe and dysuria. After 30 days of treatment, no complications were reported, and no severe complications were reported during any time period. In Gaspar's [47•] study in 2017, the study group receiving Er:YAG laser therapy had less side effects (4\%) than the control group that was treated with topical estrogen $(12 \%)$.

While these results have shown promising safety profiles for the devices, a case series published by Gordon et al. [63] in 2019 reported four cases of adverse outcomes in patients following treatment with the $\mathrm{CO}_{2}$ laser which included vaginal agglutination with resultant stenosis, and three cases of continued or worsening dyspareunia.

Ahluwali et al. [3・] published an analysis of the Manufacturer and User Facility Device Experience (MAUDE) database for events related to laser and energybased devices for vulvovaginal problems. In review of the database, 45 adverse events had been reported, including $(N=19)$ reporting vulvar, bladder, or urethral pain. Thirtythree of the patients reported that these adverse events involved chronicity including numbness, discomfort, bladder 


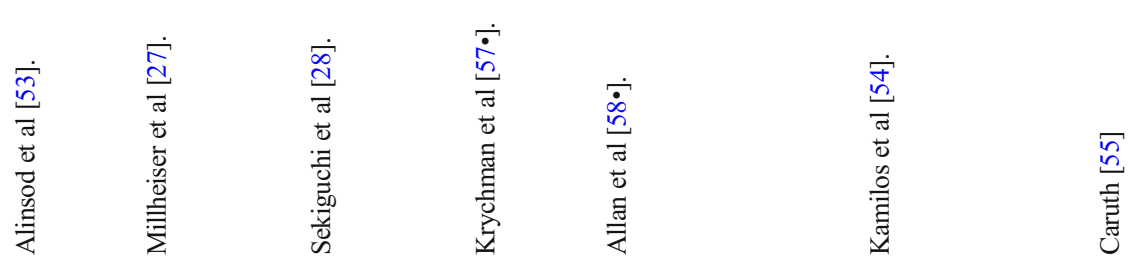

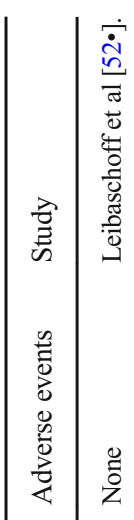

zัँ

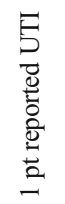

$\frac{\sqrt{n}}{\frac{\tilde{E}}{\tilde{c}}}$

:

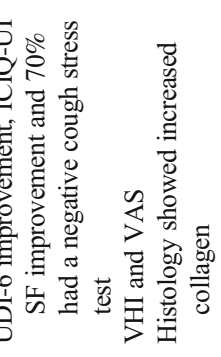

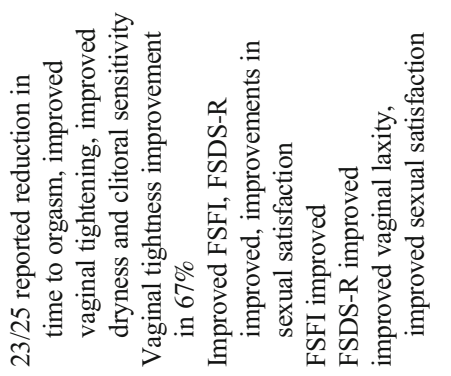

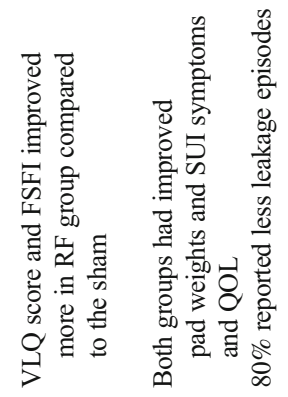

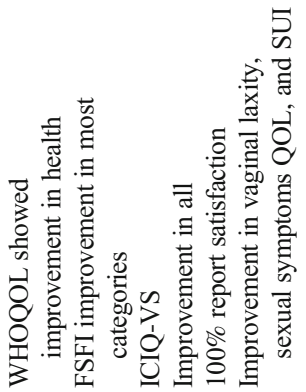

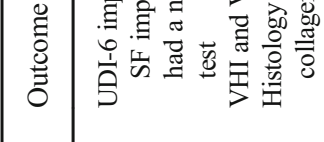

$$
\text { C. }
$$

n

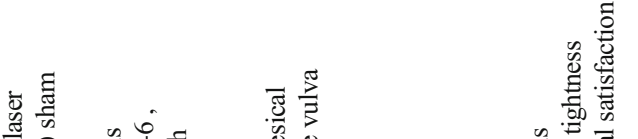

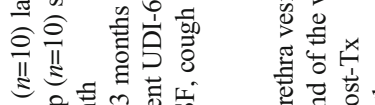

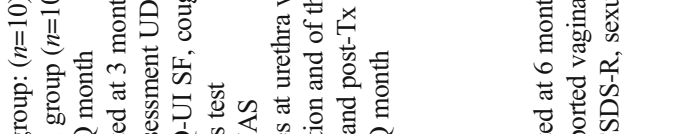

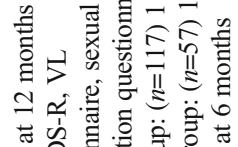

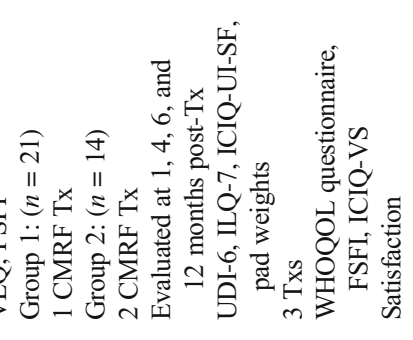

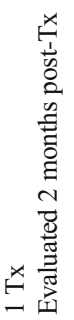

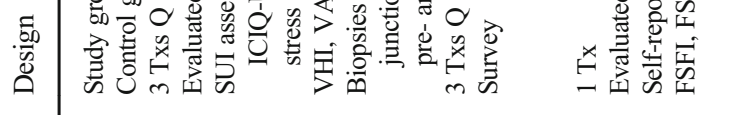

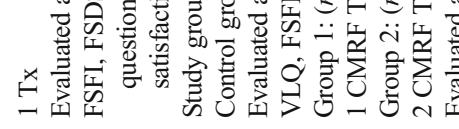

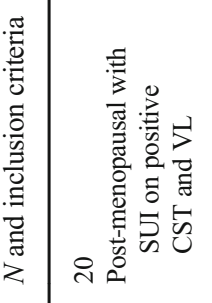

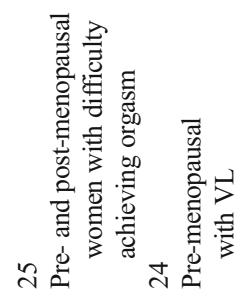

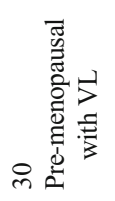

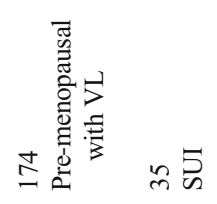

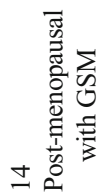

륙
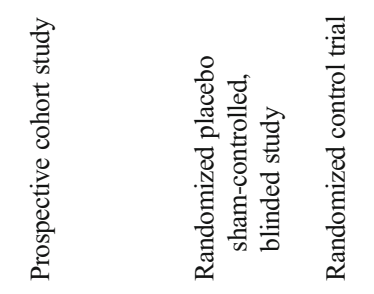

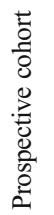
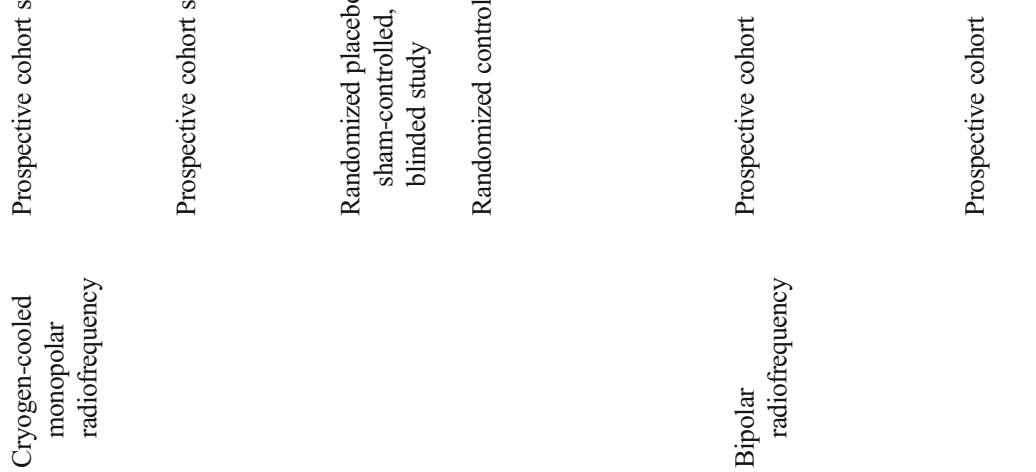


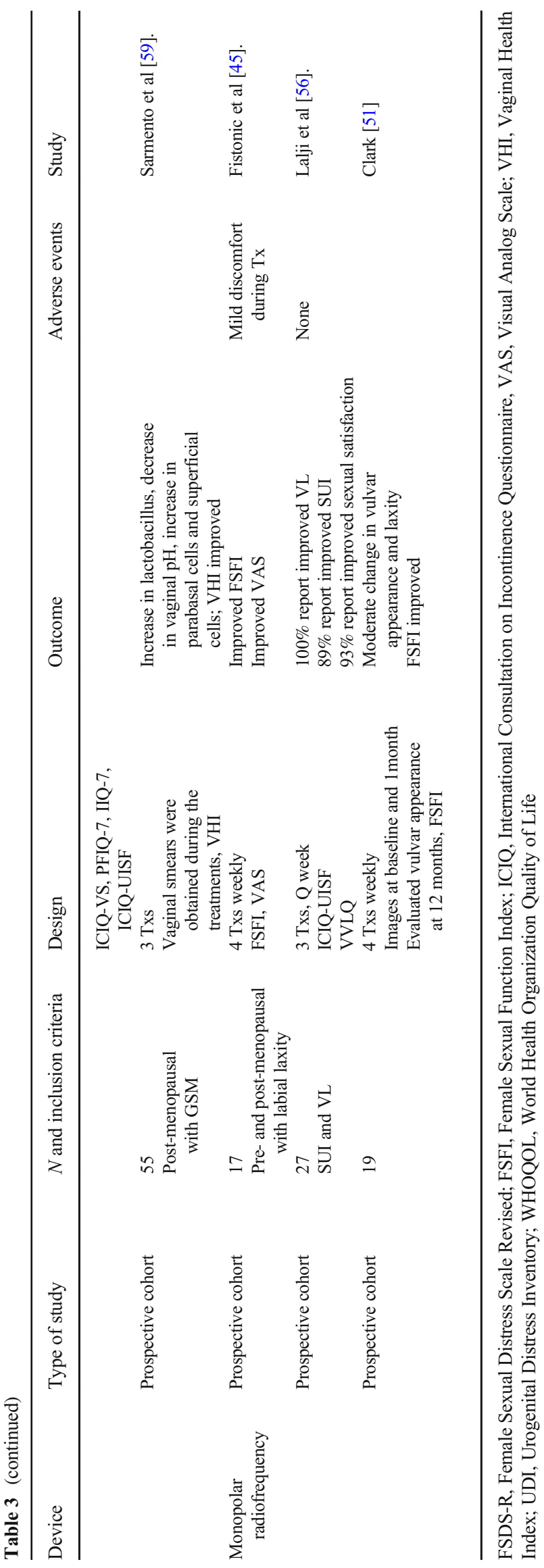

disturbance, scarring, dyspareunia, disfigurement, or worsening of previous gynecologic symptoms.

In summation, most of the information regarding the safety of the energy-based devices in their use for vulvovaginal problems supports that the energy-based devices are safe; however, there have been very few randomized control trials assessing their safety, and most studies to present day have not followed patient adverse events for a greater time period than 12 months.

\section{Societies and Organizations}

The positions of esteemed governing bodies including the US Food and Drug Administration (FDA), American College of Obstetricians and Gynecologists (ACOG), International Urogynecological Association (IUGA), the American Urogynecolgic Society (AUGS), and European Society for Sexual Medicine (ESSM) are essentially in agreement regarding the use of energy-based devices for vulvovaginal problems vaginal rejuvenation [64]. In July of 2018, the FDA issued a warning against the use of energy-based devices including laser and RF to perform vaginal rejuvenation procedures due to the fact that the safety and efficacy of the devices had not been established. The FDA stated that the devices had not been cleared for the treatment of GSM, SUI, and sexual dysfunction or for cosmetic purposes. This statement was invoked for concern that the energybased devices could cause serious adverse events including burns, scarring, dyspareunia, and chronic pain [65•]. ACOG published a position stating that though the energy-based devices show potential utility they believed there was insufficient evidence for the efficacy and long-term safety of these treatments [66]. ACOG also published the opinion that women should be counseled about the lack of high-quality data supporting the effectiveness of vaginal rejuvenation or other female genital cosmetic surgery procedures and the potential complications including pain, bleeding, infection, scarring, adhesions, altered sensation, and dyspareunia [4]. IUGA further agreed with the previous opinions in their statement in September 2018. IUGA stated that there is necessity for randomized case control trials with longterm follow-up to further investigate efficacy and safety profile of the energy-based devices in the treatment of GSM, VL, sexual dysfunction, and SUI symptoms [60]. Most recently, AUGS stated that the energy-based devices have a favorable safety profile based on short-term data, while the long-term effects of the therapies are undetermined. AUGS also commented that the patient criteria for utilizing or having contraindications to the energy-based devices as well as the appropriate treatment regimen have not been established [61].

\section{Conclusions}

The concept of vaginal rejuvenation therapy has become more popular among patients and providers. As such, newer therapy 
modalities within this genre have been produced and pursued to treat functional vaginal problems such as GSM, VL, sexual dysfunction, and SUI. Among the noninvasive therapies, the energy-based devices have appealed to patients and providers. The energy-based devices show potential to offer another line of therapy for functional vaginal problems to patients that cannot utilize current first-line therapies, such as patients with certain cancers or other health limitations, or patients that simply prefer a different type of treatment. Previously, the efficacy and safety of the energy-based devices for functional vaginal problems had been mostly limited to prospective cohort studies. While essentially all of these studies reported significant efficacy and positive safety profiles, they were limited by their design. In more recent review of the literature, randomized control trials including treatment with $\mathrm{CO}_{2}$ laser therapy and radiofrequency therapy have shown that these treatments are likely at least as effective in treating vulvovaginal problems as the standard treatment of topical vaginal estrogen and showed significant improvement compared to sham treatments [14, 37, 43, 52, 57]. No randomized control trials have been published evaluating the Er:YAG laser. While progress has been made in confirming the efficacy of these energybased devices, future studies are needed to determine the long-term safety of these devices, as current studies have been limited to evaluation of their acute safety profiles.

\section{Compliance with ethical standards}

Conflict of Interest Alyssa Bujnak MD has no conflicts of interest. Carly A Crowder MD has no conflicts of interest.

Michael L Krychman MD is a medical advisor for Viveve Medical.

Open Access This article is licensed under a Creative Commons Attribution 4.0 International License, which permits use, sharing, adaptation, distribution and reproduction in any medium or format, as long as you give appropriate credit to the original author(s) and the source, provide a link to the Creative Commons licence, and indicate if changes were made. The images or other third party material in this article are included in the article's Creative Commons licence, unless indicated otherwise in a credit line to the material. If material is not included in the article's Creative Commons licence and your intended use is not permitted by statutory regulation or exceeds the permitted use, you will need to obtain permission directly from the copyright holder. To view a copy of this licence, visit http://creativecommons.org/licenses/by/4.0/.

\section{References}

Papers of particular interest, published recently, have been highlighted as:

- Of importance

1. Desai SA, Kroumpouzos G, Sadick N. Vaginal rejuvenation: from scalpel to wands(Figure presented.). Int J Women's Dermatol.
Elsevier Inc. 2019;5:79-84. https://doi.org/10.1016/j.ijwd.2019. 02.003 .

2. Karcher C, Sadick N. Vaginal rejuvenation using energy-based devices. Int J Women's Dermatol. The Authors. 2016;2:85-8. https://doi.org/10.1016/j.ijwd.2016.05.003.

3. Ahluwalia J, Avram MM, Ortiz AE. Lasers and energy-based devices marketed for vaginal rejuvenation: a cross-sectional analysis of the MAUDE database. Lasers Surg Med. 2019;51:671-7. This article reviews reported adverse advents related to energy based devices used for vaginal problems.

4. ACOG. CO795 Elective female genital cosmetic surgery (2020). Obstet Gynecol. 2006;107:213.

5. Portman DJ, Gass MLS. Genitourinary syndrome of menopause: new terminology for vulvovaginal atrophy from the International Society for the Study of Women's Sexual Health and the North American Menopause Society. Maturitas. 2014;79:349-54.

6. Mac Bride MB, Rhodes DJ, Shuster LT. Vulvovaginal atrophy. Mayo Clin Proc. Mayo Foundation for Medical Education and Research. 2010;85:87-94. https://doi.org/10.4065/mcp.2009.0413.

7. Pieralli A, Fallani MG, Becorpi A, Bianchi C, Corioni S, Longinotti $\mathrm{M}$, et al. Fractional $\mathrm{CO} 2$ laser for vulvovaginal atrophy (VVA) dyspareunia relief in breast cancer survivors. Arch Gynecol Obstet. Springer Berlin Heidelberg. 2016;294:841-6.

8. Newman R, Campbell P, Gooneratne M, Lowenstein L, Mu G, Qureshi A, Krychman M. Genito pelvic vaginal laxity: classification, etiology, symptomatology, and treatment considerations. Curr Sex Heal Rep. 2018.

9. Pauls RN, Fellner AN, Davila GW. Vaginal laxity: a poorly understood quality of life problem; A survey of physician members of the International Urogynecological Association (IUGA). Int Urogynecol J. 2012;23:1435-48.

10. Kingsberg SA, Krychman M, Graham S, Bernick B, Mirkin S. The women's EMPOWER survey: identifying women's perceptions on vulvar and vaginal atrophy and its treatment. J Sex Med. Elsevier Inc. 2017;14:413-24. https://doi.org/10.1016/j.jsxm.2017.01.010.

11. Shifren JL, Monz BU, Russo PA, Segreti A, Johannes CB. Sexual problems and distress in united states women: prevalence and correlates. Obstet Gynecol. 2008;112:970-8.

12. Melville JL, Katon W, Delaney K, Newton K. Urinary incontinence in US women: a population-based study. Arch Intern Med. 2005; 165:537-42.

13. Lev-Sagie A. Vulvar and vaginal atrophy: physiology, clinical presentation, and treatment considerations. Clin Obstet Gynecol. 2015;58:476-91.

14. Cruz VL, Steiner ML, Pompei LM, Strufaldi R, Fonseca FLA, Santiago LHS, et al. Randomized, double-blind, placebocontrolled clinical trial for evaluating the efficacy of fractional $\mathrm{CO} 2$ laser compared with topical estriol in the treatment of vaginal atrophy in postmenopausal women. Menopause. 2018;25:21-8.

This is a randomized control, double-blind, placebo-controlled study of the efficacy of $\mathrm{CO} 2$ laser compared to topical estrogen in the treatment of vaginal atrophy.

15. Qureshi AA, Tenenbaum MM, Myckatyn TM. Nonsurgical vulvovaginal rejuvenation with radiofrequency and laser devices: a literature review and comprehensive update for aesthetic surgeons. Aesthet Surg J. 2018;38:302-11.

16. Ostrzenski A. Vaginal rugation rejuvenation (restoration): a new surgical technique for an acquired sensation of wide/Smooth Vagina. Gynecol Obstet Investig. 2012;73:48-52.

17. Barbara G, Facchin F, Buggio L, Alberico D, Frattaruolo MP, Kustermann A. Vaginal rejuvenation: current perspectives. Int $\mathrm{J}$ Women's Health. 2017;9:513-9.

18. Wilkie G, Bartz D. Vaginal rejuvenation: a review of female genital cosmetic surgery. Obstet Gynecol Surv. 2018;73:287-92.

19. Gambacciani M, Palacios S. Laser therapy for the restoration of vaginal function. Maturitas. Elsevier Ireland Ltd. 2017;99:10-5. 
https://doi.org/10.1016/j.maturitas.2017.01.012. This study compared Er:YAG laser to vaginal estrogen therapy in the treatment of GSM

20. Gaspar A, Addamo G, Brandi H. Vaginal fractional CO 2 laser: a minimally invasive option for vaginal rejuvenation. Am J Cosmet Surg. 2011;28:156-62. This is a randomized control trial compared PRP and pelvic exercises with PRP, pelvic exercises and COS laser therapy in the treatment of GSM and evaluated histological differences.

21. Zerbinati N, Serati M, Origoni M, Candiani M, Iannitti T, Salvatore $\mathrm{S}$, et al. Microscopic and ultrastructural modifications of postmenopausal atrophic vaginal mucosa after fractional carbon dioxide laser treatment. Lasers Med Sci. 2014;30:429-36.

22. Perino A, Calligaro A, Forlani F, Tiberio C, Cucinella G, Svelato A, et al. Vulvo-vaginal atrophy: a new treatment modality using thermo-ablative fractional CO2 laser. Maturitas. Elsevier Ireland Ltd. 2015;80:296-301. https://doi.org/10.1016/j.maturitas.2014. 12.006 .

23. Salvatore S, Nappi RE, Zerbinati N, Calligaro A, Ferrero S, Origoni $\mathrm{M}$, et al. A 12-week treatment with fractional $\mathrm{CO} 2$ laser for vulvovaginal atrophy: a pilot study. Climacteric. 2014;17:363-9.

24. Salvatore S, Nappi RE, Parma M, Chionna R, Lagona F, Zerbinati $\mathrm{N}$, et al. Sexual function after fractional microablative $\mathrm{CO} 2$ laser in women with vulvovaginal atrophy. Climacteric. 2015;18:219-25.

25. Vizintin Z, Rivera M, Fistonić I, Saraçoğlu F, Guimares P, Gaviria $\mathrm{J}$, et al. Novel minimally invasive VSP Er:YAG laser treatments in gynecology. J Laser Health Acad. 2012;2012:46-58 Available from: www.laserandhealth.com.

26. Gaviria JE, Lanz JA. Laser Vaginal Tightening (LVT) - evaluation of a novel noninvasive laser treatment for vaginal relaxation syndrome. J Laser Health Acad Artic J LAHA. 2012;2012:59-66 Available from: www.laserandhealth.com.

27. Millheiser LS, Pauls RN, Herbst SJ, Chen BH. Radiofrequency treatment of vaginal laxity after vaginal delivery: nonsurgical vaginal tightening. J Sex Med. 2010.

28. Sekiguchi Y, Utsugisawa Y, Azekosi Y, Kinjo M, Song M, Kubota $\mathrm{Y}$, et al. Laxity of the vaginal introitus after childbirth: nonsurgical outpatient procedure for vaginal tissue restoration and improved sexual satisfaction using low-energy radiofrequency thermal therapy. J Women's Health. 2013;22:775-81.

29. Ostrzenski A. Cosmetic gynecology in the view of evidence-based medicine and ACOG recommendations: a review. Arch Gynecol Obstet. 2011;284:617-30

30. Kim SH. Rejuvenation using platelet-rich plasma and lipofilling for vaginal atrophy and lichen sclerosus. J Menopausal Med. 2017;23: 63-8.

31. Faubion SS, Larkin LC, Stuenkel CA, Bachmann GA, Chism LA, Kagan R, et al. Consensus recommendations: management of genitourinary syndrome of menopause in women with or at high risk for breast cancer: consensus recommendations from the North American Menopause Society and the International Society for the Study of Women's Sexual Health. Menopause. 2018;25:596608.

32. Rees M, Angioli R, Coleman RL, Glasspool R, Plotti F, Simoncini $\mathrm{T}$, et al. European Menopause and Andropause Society (EMAS) and International Gynecologic Cancer Society (IGCS) position statement on managing the menopause after gynecological cancer: focus on menopausal symptoms and osteoporosis. Maturitas. Elsevier. 2020;134:56-61. https://doi.org/10.1016/j.maturitas. 2020.01.005.

33. Jha S, Wyld L, Krishnaswamy PH. The impact of vaginal laser treatment for genitourinary syndrome of menopause in breast cancer survivors: a systematic review and meta-analysis. Clin Breast Cancer. Elsevier Inc. 2019;19:e556-62. https://doi.org/10.1016/j. clbc.2019.04.007.
34. Wallace SL, St Martin B, Lee K, Sokol ER. A cost-effectiveness analysis of vaginal carbon dioxide laser therapy compared with standard medical therapies for genitourinary syndrome of menopause-associated dyspareunia. Am J Obstet Gynecol. Elsevier Inc.; 2020. https://doi.org/10.1016/j.ajog.2020.06.032

35. Di Donato V, D'Oria O, Scudo M, Prata G, Fischetti M, Lecce F, et al. Safety evaluation of fractional CO2 laser treatment in postmenopausal women with vaginal atrophy: a prospective observational study. Maturitas. Elsevier. 2020;135:34-9. https://doi.org/10. 1016/j.maturitas.2020.02.009.

36. Gambacciani M, Cervigni M, Gaspar A, Novakov Mikić A, Gaviria J, Koron N, et al. Safety of vaginal erbium laser: a review of 113, 000 patients treated in the past 8 years. Climacteric. 2020;23:S28 32.

37. Paraiso MFR, Ferrando CA, Sokol ER, Rardin CR, Matthews CA, Karram MM, et al. A randomized clinical trial comparing vaginal laser therapy to vaginal estrogen therapy in women with genitourinary syndrome of menopause: The VeLVET Trial. Menopause. 2020;27:50-6. This randomized control, single-blinded study compared vaginal $\mathrm{CO} 2$ laser therapy and vaginal estrogen cream in the treatment of GSM and did not find differences between the two groups.

38. Adabi K, Golshahi F, Niroomansh S, Razzaghi Z, Ghaemi M. Effect of the fractional $\mathrm{CO} 2$ laser on the quality of life, general health, and genitourinary symptoms in postmenopausal women with vaginal atrophy: a prospective cohort. J Lasers Med Sci. 2020;11:65-9. https://doi.org/10.15171/jlms.2020.11.

39. Lauterbach R, Dabaja H, Matanes E, Gruenwald I, Lowenstein L. The Efficacy and safety of $\mathrm{CO} 2$ laser treatment for sexual function and vaginal laxity improvement in pre-menopausal women. Lasers Surg Med. 2020:1-5.

40. Perrone AM, Tesei M, Ferioli M, De Terlizzi F, Della GAN, Boussedra S, et al. Results of a phase I-II study on laser therapy for vaginal side effects after radiotherapy for cancer of uterine cervix or endometrium. Cancers (Basel). 2020;12:1-12.

41. Eftekhar T, Forooghifar T, Khalili T, Shariat M, Haghollahi F. The effect of the $\mathrm{CO} 2$ fractional laser or premarin vaginal cream on improving sexual function in menopausal women: a randomized controlled trial. J Lasers Med Sci. 2020;11:292-8. https://doi.org/ 10.34172/jlms.2020.49. This randomized control trial compared CO2 laser therapy and vaginal estrogen cream in the treatment of GSM.

42. Takacs P, Sipos AG, Kozma B, Cunningham TD, Larson K, Lampé $\mathrm{R}$, et al. The effect of vaginal microablative fractional $\mathrm{CO} 2$ laser treatment on vaginal cytology. Lasers Surg Med. 2020:1-5.

43. Ruanphoo P, Bunyavejchevin S. Treatment for vaginal atrophy using microablative fractional $\mathrm{CO} 2$ laser: a randomized doubleblinded sham-controlled trial. Menopause. 2020;27:858-63. This randomized control, double-blinded, sham controlled trial compared $\mathrm{CO} 2$ laser treatment to sham treatment in the treatment of GSM.

44. Lapii GA, Yakovleva AY, Neimark AI, Lushnikova EL. Study of proliferative activity of vaginal epithelium in women with stress urinary incontinence treated by Er:YAG laser. Bull Exp Biol Med. 2017;163:280-3.

45. Fistonic I, Sorta Bilajac Turina I, Fistonic N, Marton I. Short time efficacy and safety of focused monopolar radiofrequency device for labial laxity improvement - noninvasive labia tissue tightening. A prospective cohort study. Lasers Surg Med. 2016;48:254-9.

46. Jorge Gaviria BKZV. up to 3-year follow up of patients with vaginal relaxation syndrome participating in laser vaginal tightening: \#186. Lasers Surg Med. 2016;48:63-4.

47. Gaspar A, Brandi H, Gomez V, Luque D. Efficacy of Erbium:YAG laser treatment compared to topical estriol treatment for symptoms of genitourinary syndrome of menopause. Lasers Surg Med. 
2017;49:160-8. This prospective study compared Er:YAG laser and vaginal estrogen with vaginal estrogen.

48. Arêas F, Valadares ALR, Conde DM, Costa-Paiva L. The effect of vaginal erbium laser treatment on sexual function and vaginal health in women with a history of breast cancer and symptoms of the genitourinary syndrome of menopause: a prospective study. Menopause. 2019;26:1052-8.

49. Reisenauer C, Hartlieb S, Schoenfisch B, Brucker SY, Neis F. Vaginal therapy of mild and moderate stress urinary incontinence using Er:YAG laser: a real treatment option. Arch Gynecol Obstet. Springer Berlin Heidelberg. 2019;300:1645-50. https://doi.org/10. 1007/s00404-019-05334-2.

50. Güneș A, Alinsod RM. A mini-review of aesthetic gynecology and leading gynecology associations' approaches to this issue. Turk Jinekoloji Obstet Dern Derg. 2018;15:105-11.

51. Clark Z. Labial tissue rejuvenation and sexual function improvement using a novel noninvasive focused monopolar radio frequency device. J Cosmet Laser Ther. Taylor \& Francis. 2018;20:66-70. https://doi.org/10.1080/14764172.2017.1368565.

52. Leibaschoff G, Izasa PG, Cardona JL, Miklos JR, Moore RD. Transcutaneous temperature controlled radiofrequency (TTCRF) for the treatment of menopausal vaginal/genitourinary symptoms. Surg Technol Int. 2016;29:149-59. This randomized control, sham treatment trial compared treatment with radio-frequency therapy to a sham treatment in the treatment of vaginal laxity and sexual dysfunction.

53. Alinsod RM. Transcutaneous temperature controlled radiofrequency for orgasmic dysfunction. Lasers Surg Med. 2016;48:641-5.

54. Kamilos MF, Borrelli CL. New therapeutic option in genitourinary syndrome of menopause: pilot study using microablative fractional radiofrequency. Einstein (Sao Paulo). 2017;15:445-51.

55. Caruth JC. Evaluation of the safety and efficacy of a novel radiofrequency device for vaginal treatment. Surg Technol Int. 2018;32: $145-9$.

56. Lalji S, Lozanova P. Evaluation of the safety and efficacy of a monopolar nonablative radiofrequency device for the improvement of vulvo-vaginal laxity and urinary incontinence. J Cosmet Dermatol. 2017;16:230-4.

57. Krychman M, Rowan CG, Allan BB, DeRogatis L, Durbin S, Yacoubian A, et al. Effect of single-treatment, surface-cooled radiofrequency therapy on vaginal laxity and female sexual function: the VIVEVE I randomized controlled trial. J Sex Med. Elsevier Inc. 2017;14:215-25. https://doi.org/10.1016/j.jsxm.2016.11.322. This randomized, placebo, sham controlled, blinded study compared treatment with radio-therapy to a sham treatment in the treatment of vaginal laxity and sexual dysfunction.
58. Allan BB, Bell S, Husarek K. A 12-month feasibility study to investigate the effectiveness of cryogen-cooled monopolar radiofrequency treatment for female stress urinary incontinence. Can Urol Assoc J. 2020;14:313-8. This randomized control trial compared one treatment with radio-frequency therapy to two treatments of radio-frequency therapy in the treatment of SUI.

59. Sarmento AC, Fernandes FS, Marconi C, Giraldo PC, EleutérioJúnior J, Crispim JC, et al. Impact of microablative fractional radiofrequency on the vaginal health, microbiota, and cellularity of postmenopausal women. Clinics (Sao Paulo). 2020;75:e1750.

60. Shobeiri SA, Kerkhof MH, Minassian VA, Bazi T. IUGA committee opinion: laser-based vaginal devices for treatment of stress urinary incontinence, genitourinary syndrome of menopause, and vaginal laxity. Int Urogynecol J. 2019;30:371-6.

61. Alshiek J, Garcia B, Minassian VA, Iglesia CB, Clark A, Sokol ER, et al. Vaginal energy based devices - AUGS clinical consensus statement. Female Pelvic Med Reconstr Surg. 2020;26:287-98.

62. Delancey JC. Editorial. Contemp Ob Gyn. 2020;12.

63. Gordon C, Gonzales S, Krychman ML. Rethinking the techno vagina: a case series of patient complications following vaginal laser treatment for atrophy. Menopause. 2019;26:423-7.

64. Romero-Otero J, Lauterbach R, Aversa A, Serefoglu EC, GarcíaGómez B, Parnham A, et al. Laser-based devices for female genitourinary indications: position statements from the European Society for Sexual Medicine (ESSM). J Sex Med. Elsevier Inc. 2020;17:841-8. https://doi.org/10.1016/j.jsxm.2020.02.013.

65. FDA. FDA warns against use of energy-based devices to perform vaginal "rejuvenation" or vaginal cosmetic procedures: FDA safety communication. Https://Www.Fda.Gov/Medical-Devices/SafetyCommunications/Fda-Warns-Against-Use-Energy-Based-DevicesPerform-Vaginal-Rejuvenation-or-Vaginal-Cosmetic. 2018;1-4.

This article is an FDA statement warning about the safety of use of energy-based devices for vaginal problems due to insufficient data.

66. ACOG. Fractional laser treatment of vulvovaginal atrophy and U . S . Food and Drug Administration clearance position statement. 2016. p. 2014-5. Available from: https://www.acog.org/clinicalinformation/policy-and-position-statements/position-statements/ 2018/fractional-laser-treatment-of-vulvovaginal-atrophy-and-usfood-and-drug-administration-clearance

Publisher's Note Springer Nature remains neutral with regard to jurisdictional claims in published maps and institutional affiliations. 